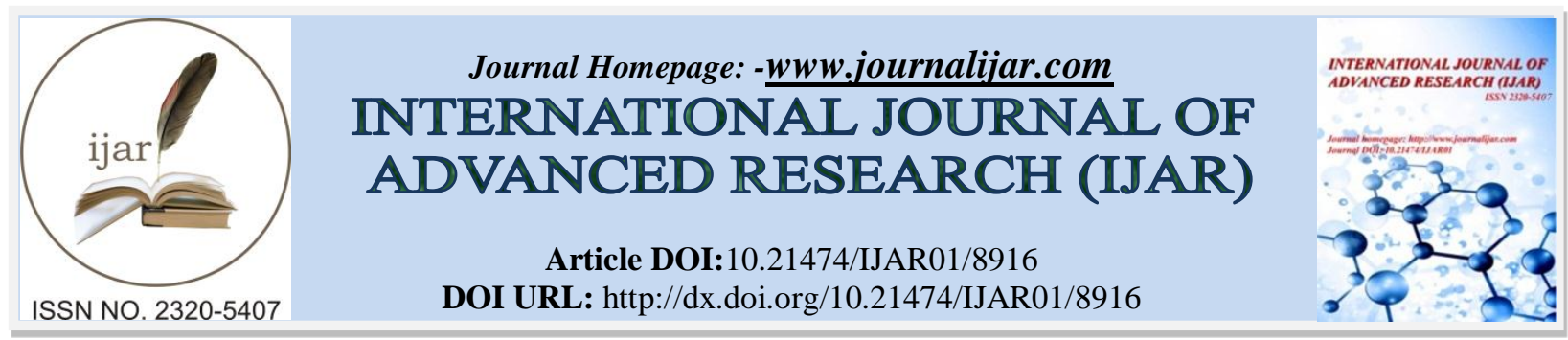

RESEARCH ARTICLE

\title{
FREQUENCY OF CONSUMPTION AND PURCHASING BEHAVIOR FOR HEALTH BEVERAGES AMONGST THE URBAN POPULATION OF VADODARA, INDIA.
}

Harsha Hirdyani ${ }^{1}$ and Mini Sheth ${ }^{2}$.

1. Senior Research Fellow, Dept. of Food and Nutrition, Faculty of Family and Community Sciences. The Maharaja Sayajirao University of Baroda, Vadodara.

2. Professor, Dept. of Food and Nutrition, Faculty of Family and Community Sciences. The Maharaja Sayajirao University of Baroda, Vadodara.

\section{Manuscript Info}

(.........................

Manuscript History

Received: 20 February 2019

Final Accepted: 22 March 2019

Published: April 2019

Key words:-

Consumption frequency; health drinks; factors affecting purchase; curd; buttermilk; fruit juices; probiotic beverages.

\begin{abstract}
To estimate the frequency of consumption and factors affecting the purchase of health drinks including curd/buttermilk, fruit juices and probiotic beverages amongst the urban population of Vadodara. A total of 429 consumers were enrolled for the study in the age group of elderlies (>60 years) adults (40-59 years), young adults (20-39 years) and adolescents (10-19 years). Sample size was calculated based on the population census of Gujarat. The consumption frequency of health drinks including curd/ buttermilk, fruit juices and probiotic beverages was studied and factors affecting the purchase of current health drinks available in the market was determined using a structured questionnaire. Frequency of consumption of curd/buttermilk (95.2\%) and fruit juices (93.3\%) was observed highest among 40-59 years of age and of probiotic beverages available commercially was observed highest (52.6\%) in the age group of 10-19 years. Results revealed that one of the major factors affects the purchase are taste $(67 \%)$ and nutrition $(65 \%)$. Other factors affecting the purchase behavior are price $(45 \%)$, brand $(37 \%)$ and appearance $(29 \%)$. The results of the present study will be useful to analyze changes in consumer habits in the food markets of a region or a country with similar traditional eating habits, in the future research. With the increasing demand for health beverages in India, this sector seems to have a bright future. Consequently, the future of Indian health food market is an account to be at a thriving pace for a long time.
\end{abstract}

Copy Right, IJAR, 2019,. All rights reserved.

\section{Introduction:-}

The Indian food and beverage industry has witnessed drastic changes in recent years. Healthier product alternatives, including beverages specifically designed to provide energy, nutrition and health to the human body, are becoming top priority (Federation of Indian Chambers of Commerce \& Industry, 2015). The desire for health and concern for ill-health has driven consumers towards these beverages. Healthier product alternatives, including beverages specifically designed to provide energy, nutrition and health to the human body, are among becoming top priority.

Corresponding Author:- Harsha Hirdyani.

Address:-Senior Research Fellow, Dept. of Food and Nutrition, Faculty of Family and Community 
The consumers for health beverages are people from the different walks of life but majority of them come from the younger and older generations.

According to the "The Euromonitor International" report (2014), Indian consumers are spending more and more on nutritional supplements to combat the effects of health problems. This indicates that people are concerned about their health. Recent trends in final food demand show that the concept of food has undergone a radical transformation. In addition to the nutritional and sensory properties of food, consumers are also well aware about their important role in the maintenance of health, on psycho-physical well-being and prevention of certain diseases. (Azzurra and Paola, 2009). With urbanisation and exposure to the West, Indian consumers today are increasingly becoming conscious of their lifestyle including food and beverage choices, in some cases prompting a shift from colas to healthier options such as juices, milk-based flavoured beverages, etc. The market share of fruit juices, nectars and juice drinks stands at around $25.1 \%$, which is still less than that of carbonated drinks (approx 47.9\%), as per KPMG (Thomson, 2012). The Indian market is evolving with the growing health awareness. The new generation is ready to pay a premium price for functional advantage from such health beverage products. Rising knowledge about wellness and health along with inclining expenditure on beverages has increased the number of consumers accepting such beverages. Thus, considering the increasing health consciousness amongst Indian populace and a strong pull towards the health beverages industry following study was conducted to estimate the consumption of common health beverages like curd/buttermilk, fruit juices and probiotic beverages and factors affecting the purchase behavior of such health beverages in Vadodara, India.

\section{Materials and methods:- Sample size selection}

Sample size was calculated based on the population census of Gujarat (Census of India, 2011; Directorate of Economics and Statistics Government of Gujarat, 2011) for all the different age groups. All the subjects selected were a representative of the total percentage population of that age group (Census of India, 2011; Directorate of Economics and Statistics Government of Gujarat, 2011). A total of 429 consumers were enrolled for the study in the age group of elderlies (>60 years) adults (40-59 years), young adults (20-39 years) and adolescents (10-19 years). Children below 10 years of age were excluded. Forty two subjects were enrolled from old age homes in the age group of $>60$ years. Similarly 106 subjects from the age group of $40-59$ years and 186 subjects from the age group of 20-39 years were selected using convenient sampling technique from a Food-fest organized at Faculty of Family and Community Sciences, Vadodara. Ninety five subjects and 89 subjects were selected from the age group of 10-19 years from the college students in the Faculty of Family and Community Sciences and The Experimental school, MS University of Baroda, Vadodara.

\section{Ethical considerations}

The Medical Ethics committee of the Foods and Nutrition Department, The M.S. University of Baroda approved the study proposal and provided the Medical ethics approval number (F.C.Sc/FND/ME/55). Permissions were obtained from the (i) Head and Dean of Dept. of Food and Nutrition, Faculty of Family and Community Sciences, The MS University of Baroda to enroll the participants of Food Fest held in the campus, (ii) Principles of Experimental School of The MS University of Baroda, Vadodara and (iii) Head officer of Jalaram Vrudhashram, Nizampura and Premdas Jalaram ashram, Warasia. Duly filled informed consent was obtained from the participants prior to the enrolment, who agreed to participate in the study.

\section{Development and implementation of the questionnaire}

The questions in the semi-structured questionnaire were both qualitative and quantitative on the consumption pattern of curd/buttermilk, fruit juices, probiotic beverages and also the factors affecting the purchase of commercially available health beverages. In addition, observation criteria during the interview were used. Care was taken that the questions did not contain any information about specific products, brands and prices to avoid influencing the information to be obtained and the consumer buying preferences. Additionally, no information was given about the nutritional value of the products and their health effects. A pilot test was performed by applying the questionnaire to a group of 20 to 30 people to evaluate the clarity of the questions. After the pilot, it was observed that all questions were sufficiently clear, and was given to respondents to elicit their answers. 


\section{Frequency of consumption of health drinks}

The frequency of consumption of curd/ buttermilk, fruit juices and probiotic beverages was studied using a set of questions to understand the current pattern of consumption of health drinks. Details of the number of times these drinks were consumed on a daily, monthly, twice a month or never basis was elicited using the questionnaire.

Consumer view on the factors affecting the purchase of health drinks in the market

Consumer responses were asked about the factors affecting their purchase of current health drinks in the market. Choices given to the respondents were- Appearance, Taste, Texture, Nutrition, Convenience, Price, Odour, Innovation and Brand.

\section{Statistical analysis}

The data collected from the questionnaires were tabulated in Microsoft Excel and analyzed using the software SPSS version 21.0 and $p<0.05$ values were considered significant. Variables associated with consumption and purchase of health drinks were evaluated using the Pearson's Chi-square test.

\section{Results:-}

\section{Frequency of consumption of curd/ buttermilk by consumers}

As seen in Table 1 a significant difference $(p<0.001)$ was found in the frequency of consumption of curd/ buttermilk amongst all the age groups. Majority of the subjects consumed buttermilk or curd on daily basis or more than once a week with highest (95.2\%) consumption in the age group of 40-59 years and least (76.1\%) in above 60 years of age.

Table 1:-Frequency of consumption of curd/ buttermilk

\begin{tabular}{|c|c|c|c|c|c|c|}
\hline Age Group & Daily & Once a month & $\begin{array}{ll}\text { Twice } & \text { a } \\
\text { month }\end{array}$ & Never & $\begin{array}{l}\text { Chi } \\
\text { square }\end{array}$ & p-value \\
\hline 10-19 $(\mathrm{n}=95)$ & $80(84.2)$ & $8(8.4)$ & $4(4.2)$ & $3(3.1)$ & \multirow{4}{*}{21.49} & \multirow{4}{*}{0.000} \\
\hline $\mathbf{2 0 - 3 9}(\mathrm{n}=186)$ & $164(88.1)$ & $10(5.3)$ & $1(1)$ & $11(5.9)$ & & \\
\hline 40-59 $(n=106)$ & $101(95.2)$ & $2(1.8)$ & $0(0)$ & $3(2.8)$ & & \\
\hline$>60(\mathrm{n}=42)$ & $32(76.1)$ & $9(21.4)$ & $0(0)$ & $1(2.3)$ & & \\
\hline
\end{tabular}

Note: Figures in parenthesis indicate percentages

Frequency of consumption of fruit juices by consumers

As seen in Table 2 a significant difference $(\mathrm{p}<0.001)$ was found in the frequency of consumption of fruit juices amongst all the age groups. Consumption of fruit juices was found highest in the age group of 40-59 years (93.3\%) followed by the age group of $20-39$ years $(89.7 \%)$. Daily consumption was found least $(45.2 \%)$ in elderlies and $30.9 \%$ of the consumers stated that they never consume fruit juices.

Table 2:-Frequency of consumption of fruit juice

\begin{tabular}{|c|c|c|c|c|c|c|}
\hline Age Group & Daily & Once a month & $\begin{array}{l}\text { Twice a } \\
\text { month }\end{array}$ & Never & Chi Square & p-value \\
\hline 10-19 $(\mathrm{n}=95)$ & $80(84.2)$ & $9(9.4)$ & $1(1)$ & $1(1)$ & \multirow{4}{*}{80.38} & \multirow{4}{*}{0.000} \\
\hline 20-39 $(\mathrm{n}=186)$ & 167 (89.7) & $13(6.9)$ & $13(6.9)$ & $6(3.2)$ & & \\
\hline 40-59 $(\mathrm{n}=106)$ & 99 (93.3) & $3(2.8)$ & $1(0.9)$ & $3(2.8)$ & & \\
\hline$>60(\mathrm{n}=42)$ & $19(45.2)$ & $2(4.7)$ & $8(19)$ & $13(30.9)$ & & \\
\hline
\end{tabular}

Note: Figures in parenthesis indicate percentages

Frequency of consumption of probiotic beverages by consumers

As seen in Table 3, a significant difference $(\mathrm{p}<0.001)$ was found in the frequency of consumption of probiotic beverages amongst all the age groups. Daily consumption and more than once a week was found highest in the age group of 10-19 years (52.6\%) followed by 20-39 years (37\%). Fifty seven percent from the age group stated they never consume probiotic drinks followed by elderlies. Overall it was seen that out of all the subjects $37.7 \%$ consumed probiotic beverages either on daily basis or more than once a week.

Table 3:-Frequency of consumption of probiotic drinks (Chi Square test)

\begin{tabular}{|l|l|l|l|l|l|l|}
\hline Age Group & Daily & Once a month & Twicea month & Never & Chi Square & p-value \\
\hline 10-19 $(\mathrm{n}=95)$ & $50(52.6)$ & $16(16.8)$ & $6(6.3)$ & $17(17.8)$ & & \\
\hline
\end{tabular}




\begin{tabular}{|l|l|l|l|l|l|l|}
\hline $\mathbf{2 0 - 3 9}(\mathrm{n}=186)$ & $69(37)$ & $38(20.4)$ & $10(5.3)$ & $69(37)$ & \multirow{3}{*}{3} & \multirow{3}{*}{0.000} \\
\cline { 1 - 5 } $\mathbf{4 0 - 5 9}(\mathrm{n}=106)$ & $31(29.2)$ & $14(13.2)$ & $4(3.7)$ & $57(53.7)$ & & \\
\cline { 1 - 5 }$(\mathrm{n}=42)$ & $12(28.5)$ & $6(14.2)$ & $3(7.1)$ & $21(50)$ & & \\
\hline
\end{tabular}

Note: Figures in parenthesis indicate percentages

\section{Factors affecting the purchase of health drinks}

Consumer's buying behaviour is influenced by cultural, social, personal, psychological factors. In the present study factors affecting the purchase of health drinks by consumers were evaluated. Results depicted (Fig 1, Tables 4-12) that one of the major factors affects the purchase are taste $(67 \%)$ and nutrition $(65 \%)$. Other factors affecting the purchase behaviour are price $(45 \%)$, brand (37\%) and appearance $(29 \%)$.

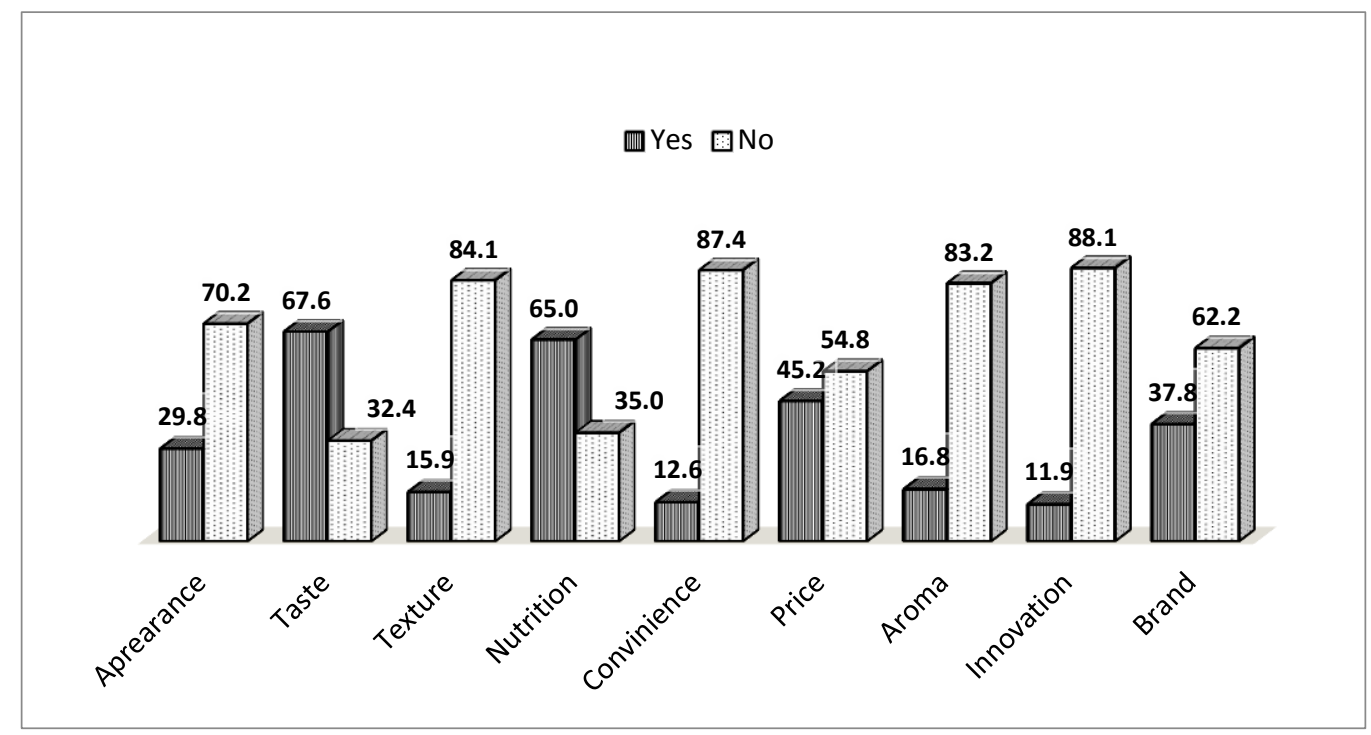

Fig 1:-Factors affecting purchase of health drinks by the consumers

Table 4:-Appearance as a factor for purchase of health drinks by the consumers

\begin{tabular}{|c|c|c|c|c|}
\hline Age Group & Yes & No & Chi Square (X2) & $P$ value \\
\hline $10-19(n=95)$ & $20(19)$ & $75(81)$ & \multirow{4}{*}{21.96} & \multirow{4}{*}{0.000} \\
\hline $20-39(n=186)$ & $67(36)$ & $119(64)$ & & \\
\hline 40-59 $(n=106)$ & $39(36.7)$ & $67(63.3)$ & & \\
\hline$>60(n=42)$ & $2(4.7)$ & $40(95.3)$ & & \\
\hline
\end{tabular}

Note: Figures in parenthesis indicate percentages

Table 5:-Taste as a factor for purchase of health drinks by the consumers

\begin{tabular}{|c|c|c|c|c|}
\hline Age Group & Yes & No & Chi Square (X2) & P value \\
\hline $\mathbf{1 0 - 1 9}(n=95)$ & $58(61)$ & $37(39)$ & & \\
\hline $\mathbf{2 0 - 3 9}(n=186)$ & $133(71.5)$ & $53(28.5)$ & \multirow{2}{*}{0.000} \\
\hline $\mathbf{4 0 - 5 9 ( n = 1 0 6 )}$ & $70(66)$ & $36(34)$ & & \\
\hline$>60(n=42)$ & $29(69)$ & $13(31)$ & & \\
\hline
\end{tabular}

Note: Figures in parenthesis indicate percentages

Table 6:-Texture as a factor for purchase of health drinks by the consumers

\begin{tabular}{|c|c|c|c|c|}
\hline Age Group & Yes & No & Chi Square (X2) & P value \\
\hline $\mathbf{1 0 - 1 9}(n=95)$ & $12(12.6)$ & $83(87.4)$ & & \\
\hline $\mathbf{2 0 - 3 9}(n=186)$ & $34(18.2)$ & $152(81.8)$ & \multirow{2}{*}{3.56} & \\
\hline $\mathbf{4 0 - 5 9 ( n = 1 0 6 )}$ & $13(12.2)$ & $93(87.8)$ & & \\
\hline$>60(n=42)$ & $9(21.4)$ & $33(78.6)$ & & \\
\hline
\end{tabular}

Note: Figures in parenthesis indicate percentages 
Table 7:-Nutrition as a factor for purchase of health drinks by the consumers

\begin{tabular}{|c|c|c|c|c|}
\hline Age Group & Yes & No & Chi Square (X2) & P value \\
\hline 10-19 $(n=95)$ & $63(66.3)$ & $32(33.7)$ & & \\
\cline { 1 - 3 } $\mathbf{2 0 - 3 9 ( n = 1 8 6 )}$ & $133(71.5)$ & $53(28.5)$ & 53.75 & 0.000 \\
\hline 40-59(n=106) & $77(72.6)$ & $29(27.4)$ & & \\
\hline$>60(n=42)$ & $6(14.2)$ & $36(85.8)$ & & \\
\hline
\end{tabular}

Note: Figures in parenthesis indicate percentages

Table 8:-Convenience as a factor for purchase of health drinks by the consumers

\begin{tabular}{|c|c|c|c|c|}
\hline Age Group & Yes & No & Chi Square (X2) & P value \\
\hline $\mathbf{1 0 - 1 9}(n=95)$ & $11(11.5)$ & $84(88.5)$ & & \\
\cline { 1 - 3 } $\mathbf{2 0 - 3 9 ( n = 1 8 6 )}$ & $31(16.6)$ & $155(83.4)$ & 6.19 & 0.000 \\
\hline $\mathbf{4 0 - 5 9 ( n = 1 0 6 )}$ & $10(9.4)$ & $96(90.6)$ & & \\
\hline$>60(n=42)$ & $2(4.7)$ & $40(95.3)$ & & \\
\hline
\end{tabular}

Note: Figures in parenthesis indicate percentages

Table 9:-Price as a factor for purchase of health drinks by the consumers

\begin{tabular}{|c|c|c|c|c|}
\hline Age Group & Yes & No & Chi Square (X2) & P value \\
\hline $\mathbf{1 0 - 1 9}(n=95)$ & $52(54.7)$ & $43(45.3)$ & & \\
\cline { 1 - 3 } $\mathbf{2 0 - 3 9}(n=186)$ & $88(47.3)$ & $98(52.7)$ & \multirow{2}{*}{9.08} & 0.000 \\
\hline $\mathbf{4 0 - 5 9 ( n = 1 0 6 )}$ & $41(38.6)$ & $65(61.4)$ & & \\
\hline$>60(n=42)$ & $13(30.9)$ & $29(69.1)$ & & \\
\hline
\end{tabular}

Note: Figures in parenthesis indicate percentages

Table 10:-Aroma as a factor for purchase of health drinks by the consumers

\begin{tabular}{|c|c|c|c|c|}
\hline Age Group & Yes & No & Chi Square (X2) & P value \\
\hline $\mathbf{1 0 - 1 9}(n=95)$ & $9(9.4)$ & $86(90.6)$ & & \\
\hline $\mathbf{2 0 - 3 9}(n=186)$ & $42(22.5)$ & $144(77.5)$ & \multirow{2}{*}{0.08} & \\
\hline $\mathbf{4 0 - 5 9 ( n = 1 0 6 )}$ & $14(13.2)$ & $92(86.8)$ & & \\
\hline$>60(n=42)$ & $7(16.6)$ & $35(83.4)$ & & \\
\hline
\end{tabular}

Note: Figures in parenthesis indicate percentages

Table 11:-Innovation as a factor for purchase of health drinks by the consumers

\begin{tabular}{|c|c|c|c|c|}
\hline Age Group & Yes & No & Chi Square (X2) & P value \\
\hline $10-19(n=95)$ & $10(10.5)$ & $85(89.5)$ & \multirow{4}{*}{9.25} & \multirow{4}{*}{0.000} \\
\hline $20-39(n=186)$ & $30(16.1)$ & $156(83.9)$ & & \\
\hline 40-59 $(n=106)$ & $11(10.3)$ & $95(89.7)$ & & \\
\hline$>60(n=42)$ & $0(0)$ & $42(100)$ & & \\
\hline
\end{tabular}

Note: Figures in parenthesis indicate percentages

Table 12:-Brand as a factor for purchase of health drinks by the consumers

\begin{tabular}{|c|c|c|c|c|}
\hline Age Group & Yes & No & Chi Square (X2) & $P$ value \\
\hline $10-19(n=95)$ & $39(41)$ & $56(59)$ & \multirow{4}{*}{0.98} & \multirow{4}{*}{0.000} \\
\hline $20-39(n=186)$ & $66(35.4)$ & $120(64.6)$ & & \\
\hline 40-59 $(n=106)$ & $40(37.7)$ & $66(62.3)$ & & \\
\hline$>60(n=42)$ & $17(40.4)$ & $25(59.6)$ & & \\
\hline
\end{tabular}

Note: Figures in parenthesis indicate percentages

\section{Discussion:-}

Frequency of consumption of curd and buttermilk was studied in the present study. Results depicted that majority of people (84-95\%) in all the age groups consume curd or buttermilk on daily basis. These results are similar to the results documented in the study conducted by Priyanka and Mallika, 2013 where 626 volunteers (81.3\%) were 
consuming curd since childhood. Curd and buttermilk/ lassi consumption pattern was studied in the sample population of North, Central and south India. More than one out of five sample population never consumed curd, while majority consumed 1 portion daily. According to the report of Milk and Dairy Products in India - Production, Consumption and Exports, it was estimated that almost 10 per cent of liquid milk bought by households is converted into curd, as majority of Indian households consume curd on daily basis (Chawla et al, 2009). In another study conducted in Maharashtra, analysis showed that 95.83 per cent of households regularly consumed dairy foods like curd, lassi, buttermilk etc. (Govindrao, 2012). Deaton et al., (2009) states that buttermilk widely available often free of cost, in many villages of India, particularly in the north-western region. Consumption of 1 portion of curd daily was more common in age 45-54 years, which is similar to the results of our study. A contradictory result was found for buttermilk which stated that one out of four participants never drink buttermilk/lassi while only $14 \%$ drink 1 portion daily (Satija et al, 2013; Kumari et al, 2018).

The consumption pattern of fruit juices in the present study documented 93\%, 89\% and 84\% in the age groups of 40 59yrs, 20-39yrs and 10-19yrs respectively. This may be due to rise in the disposable income, people adopting Western culture, health awareness and import of fruits to India are among the top most factors to drive the juice business in India (Granqvist and Ritvala, 2016). The rising number of health-conscious consumers is giving a boost to fruit juices; it has been observed that consumers are shifting from fruit-based drinks to fruit juices as they consider the latter a healthier breakfast/snack option.

Consumption of probiotic beverages was studied in the present study, and it was observed that the consumption rate was lesser as compared to curd, buttermilk or fruit juices. Results documented that the maximum consumption was $52 \%$ in the age group of 10-19yrs, followed by $37 \%$ and $31 \%$ in the age group of $20-39$ yrs and $40-59 \mathrm{yrs}$. This may be due to lack of knowledge and awareness amongst the consumers for probiotics. Thirty eight percent consumer had never consumed any kind of probiotic beverages available in market. A study conducted in Punjab documented that out of 220 adult respondents only $60.5 \%$ of respondents were familiar with the word probiotic out which only $36.8 \%$ have ever consumed probiotic. The consumption rate is higher in the age group of 10- 19 yrs which may be due to their education and exposure to new innovations and updated knowledge about health products (Swetaa et al, 2018; Khongrangjem et al, 2017, Antony and Bhatti, 2015). A study was conducted on the nutrition awareness of the students of Government Degree College, Jammu and Kashmir. Sample was selected randomly of 100 students of various departments and Nutrition awareness of the students was measured regarding nutrition and health status, health foods etc, and results documented that $76 \%$ of the students have good and excellent knowledge about health foods and other parameters studied (Ahmad et al, 2018).

Acceptance of a food is basically the result of the interaction between food and man at a certain moment (Shepherd, 2007). Food characteristics (chemical and nutritional composition, physical structure and properties), consumer characteristics (genetic, age group, gender, physiological and psychological state) and those of the consumer's environment (family and cultural habits, religion, education, fashion, price or convenience) the influence of consumers' decision to accept or reject a food (Shepherd, 2007; Shepherd and Sparks, 2011). Several studies have been conducted to examine how consumers evaluate different product attributes in numerous food products. Health, nutrition, taste, price, convenience are some of the criteria consumers use to determine which product is more attractive (Adinsi et al, 2015).

\section{Conclusion:-}

Due to increasing health concerns amidst Indian consumers, the importance of having a healthy lifestyle has been witnessed. People have started to focus on the nutrient content and quality of the food they eat due to which consumption of health beverages and other health food products have increased. The overall consumption and the increasing affinity for health foods and beverages has led the market to grow at a faster pace due to the growing awareness and the lifestyle shift within the urban population. The results of the present study will be useful to analyze changes in consumer habits in the food markets of a region or a country with similar traditional eating habits, in the future research. Also further researches can also be conducted on the impact of changes in the lifestyle which occurs in contemporary society with consumers nutrition habits. With the increasing demand for health beverages in India, this sector seems to have a bright future. Consequently, the future of Indian health food market is an account to be at a thriving pace for a long time.

\section{Competing interests}

The authors declare that they have no competing interests 


\section{Funding}

University Grants Commission- Basic Scientific Research Scholarship (year 2015)

\section{Acknowledgements:-}

Gujarat Co-operative Milk Marketing Federation Ltd. - AMUL India Ltd; Genelon Institute of Life Sciences, Bangalore

\section{References:-}

1. Adinsi L, Akissoe NH, Dalode-Vieira G, Anihouvi V, et al. (2015). Sensory evaluation and consumer acceptability of a beverage made from malted and fermented cereal: case of gowe from Benin. Food Science \& Nutrition, 3(1), 1-9

2. Ahmad M, Mohid-u-din S and Qadir M. (2018). A survey study of nutritional awareness among students. International Journal of Physiology, Nutrition and Physical Education, 3(1), 1796-1797

3. Antony M and Bhatti RK. (2015). Junk food consumption and knowledge about its ill effects among teenagers: a descriptive study. IJSR, 4(6), 1133-1136.

4. Azzurra A and Paola P. (2009). Consumers' behaviours and attitudes toward healthy food products: The case of Organic and Functional foods. European Association of Agricultural Economists, 113, 1-14

5. Census of India, 2011 (available at: http://censusindia.gov.in/, assessed on $15^{\text {th }}$ March 2017)

6. Chawla A, Chawla N, Pant Y, Hindustan Studies \& Services Ltd., et al. (2009). Milk and Dairy Products in India - Production, Consumption and Exports. http://www.hindustanstudies.com/files/dairysept09report.pdf (assessed on 10th Oct 2018)

7. Deaton, A. and Jean, D. (2009). Food and Nutrition in India: Facts and Interpretations February 14, EPW Economic \& Political Weekly, X liv, 7, 42-65.

8. Directorate of Economics and Statistics Government of Gujarat, 2011 (Assessed on $19^{\text {th }}$ April 2017)

9. Federation of Indian Chambers of Commerce and Industry (FICCI). [Cited: 27 ${ }^{\text {th }}$ December 2015, 16:45 hrs]. Available at: http://ficci.in/

10. Govindrao HP. (2012). A study on consumption pattern and consumer preferences for fermented fucntional dairy foods in metropolitan Maharashtra. http://krishikosh.egranth.ac.in/bitstream/1/5810032627/1/M-2795.pdf

11. Granqvist N and Ritvala T. (2016). Beyond prototypes: Drivers of market categorization in functional foods and nanotechnology. Journal of Management Studies, 53(2): 210-237

12. Khongrangjem T, Dsouza SM, Prabhu P, Daange VB et al. (2017). A study to assess the knowledge and practice of fast food consumption among Pre-University students in Udupi Taluk, Karnataka, India. Clinical Epidemiology and Global Health, 26, 1-4

13. Kumari S, Kulshrestha K, Prasad J, et al. (2018). Study the Consumption Pattern of Milk and Milk Products along with Animal Foods in Kumaon Region of Uttarakhand, India. Int.J.Curr.Microbiol.App.Sci, 7(4), 250-254

14. Priyanka BV and Mallika KJ. (2013). Dietic practice of curd - demographic survey. Ayurpharm Int J Ayur Alli Sci, 2(12), $364-371$

15. Satija A, Agrawal S, Bowen L, Khandpur N, et al. (2013). Association between Milk and Milk Product Consumption and Anthropometric Measures in Adult Men and Women in India: A Cross-Sectional Study. PLoS ONE, 8(4), 607-39

16. Shepherd R and Sparks P. (2011). Modelling food choice. In: H. J. H. MacFie \& 650 D. M. Thomson (Eds.). Measurement of Food Preferences, 202-223. Blackie Academic \& Professional, London

17. Shepherd R. (2007). Factors influencing food preferences and choice. In: Shepherd (ed.), Handbook of the Psychophysiology of Human Eating, 3-24, John Wiley and Sons Ltd, Chichester, UK

18. Swetaa A, Gayathri R, Vishnu V. (2018). Awareness on balanced diet and eating practices among college students - A survey. Drug Invention Today, 10(8), 1408-1410

19. The Euromonitor Report (2014). [Cited: 27 $7^{\text {th }}$ December 2015, 16:45 hrs] Available at: http://www.euromonitor.com/in

20. Thomson M. (2012). Ten most popular beverages around the world, available at: www.mrtop10.com/ 10_most_popular_beverages_around_the_world-3295 (accessed 03 January 2016). 